\title{
Stress and its association with working efficiency of junior doctors during three postgraduate residency training programs
}

This article was published in the following Dove Press journal:

Neuropsychiatric Disease and Treatment

10 December 2015

Number of times this article has been viewed

\section{Hamza Mohammad \\ Abdulghani' \\ Mohammed Meteb Al-harbi² \\ Mohammad Irshad' \\ 'Department of Medical Education, \\ ${ }^{2}$ Department of Family and \\ Community Medicine, College of \\ Medicine, King Saud University, \\ Riyadh, Kingdom of Saudi Arabia}

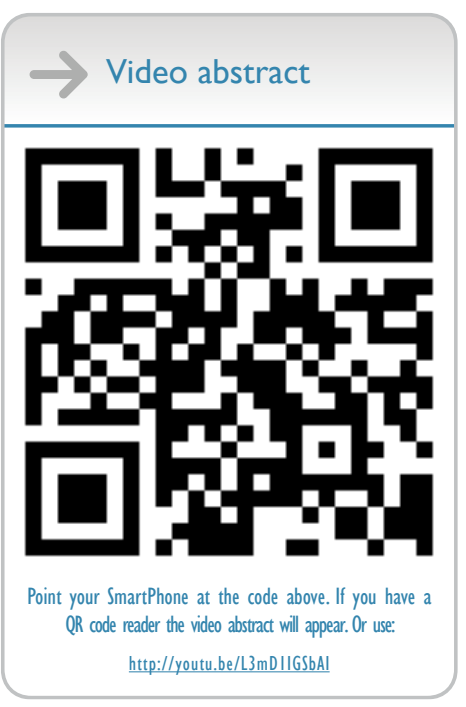

Correspondence: Hamza Mohammad Abdulghani

Department of Medical Education, College of Medicine, King Saud University, PO Box 230 155, Riyadh

I I 32 I, Kingdom of Saudi Arabia

Tel +966 | | 4699 I77

Fax+966 I| 467 I967

Email hamzaabg@gmail.com
Background: The residency training period in the medical profession is well known for physical and mental stress, which may affect cognitive function and practical life. The aims of this study were to assess prevalence of stress among the resident trainees of the three medical specialties of Saudi Commission for Health Specialties (SCHS) training programs, namely, Internal Medicine, Emergency Medicine, Family Medicine, and their association with training years, sex, and marital status. This study also aimed to correlate the stress levels with the working efficiency and self-perceived general health problems.

Participants and methods: Resident trainee physicians of SCHS were invited to complete a stress inventory Kessler 10, which is used for stress measurement. Pearson's chi-square test $\left(\chi^{2}\right)$ and odds ratios (ORs) were used to quantify the associations between categorical variables. A $P$-value of $<0.05$ was considered statistically significant.

Results: A total of 318 (out of 389 , with the response rate of $82 \%$ ) resident trainees participated in this study. The mean ( \pm standard deviation) age of the study population was 27.9 $( \pm 1.6)$ years. The results showed $70.4 \%$ of resident trainees had stressful conditions, which consisted of severe stress: $22.6 \%$, moderate stress: $20.4 \%$, and mild stress: $27.4 \%$. During the 1 st year $(\mathrm{R}-1)$, moderate stress $(\mathrm{OR}=5.87 ; 95 \%$ confidence interval $=2.93-17.79 ; P=0.001)$ and severe stress $(\mathrm{OR}=11.15 ; 95 \%$ confidence interval $=4.35-28.51 ; P=0.0001)$ levels were quite high. The highest stress level was found in Emergency Medicine (80.5\%), followed by Internal Medicine (73.6\%), and Family Medicine (63.2\%) $\left(\chi^{2}=6.42 ; P=0.04\right)$. The stress level decreased with the increase of years of training in Emergency Medicine $\left(\chi^{2}=23.76 ; P<0.0001\right)$ and Internal Medicine $\left(\chi^{2}=60.12 ; P<0.0001\right)$, whereas increased in Family Medicine $\left(\chi^{2}=11.80\right.$; $P=0.008)$. High stress level was significantly associated with absence from duty days $\left(\chi^{2}=28.48\right.$, $P<0.0001)$, inefficient day activities $\left(\chi^{2}=39.15 ; P<0.0001\right)$, and general health problems $\left(\chi^{2}=45.27 ; P<0.0001\right)$ of resident trainees.

Conclusion: We found significantly high levels of stress among the resident trainees of SCHS. High levels of stress may have an effect on their working efficiency and general physical health. The high stress level decreased efficient day activity and made the trainees absent from the workplace.

Keywords: postgraduate, stress, residency training, specialties

\section{Introduction}

Emotional impairment, depression, and burnout are commonly reported during residency training programs. ${ }^{1,2}$ These symptoms generally increase due to the high expectation of proficient clinicians, educators, researchers, and administrators at the end of the training programs. ${ }^{3}$ Some recent studies reported that during residency training, residents are becoming more cynical, less humanistic, depressive, and even reach the burnout stage. ${ }^{4-6}$ 
In fact, these symptoms are triggered by a set of physiological reactions when a worrisome situation is perceived during the period of residency training. When a situation becomes stressful, it triggers the activation of the hypothalamic-pituitary-adrenal axis, whereby the secretion of the stress hormones is triggered. ${ }^{7}$ The low-level secretion of stress mediators is essential for the adequate encoding of emotionally relevant information and enhancement of memory. ${ }^{8} \mathrm{~A}$ stress hormone (norepinephrine) is needed to create new memories, improves mood, helps make problems feel more like challenges, and encourages creative thinking that stimulates the brain to grow new connections. ${ }^{9}$ Conversely, high-level secretion can contribute to reduced concentration and cognitive impairment. ${ }^{10}$ However, chronic and oversecretion adversely affects brain function, especially, on an individual's memory. Too much secretion of cortisol (another stress hormone) can prevent the brain from laying down a new memory and can make it difficult to think or retrieve long-term memories and shut down the self-regulation system of the brain.

Also, high level of stress can result in persistent of general physical problems such as increased breathing, heart rate, blood pressure, headaches, reduced eyesight, stomachaches, digestive problems, and facial, neck, and back pain. ${ }^{11}$ Other consequences of high levels of stress include anger, irritability, anxiety, poor sleep, fatigue, and depression. ${ }^{12}$ Prolonged high levels of stress may also cause burnout in medical professionals. ${ }^{13}$

The Saudi Commission for Health Specialties (SCHS) is a national body responsible for supervising and accrediting the various health specialty residency training programs. SCHS also laid down residency training criteria for the medical graduates to work as a specialist in the Kingdom of Saudi Arabia. ${ }^{14}$ SCHS assists the newly selected residents to acquire competent knowledge, skills, and expertise for their certification as specialists in different branches of medicine. ${ }^{15}$

There is no local or regional study which has investigated the prevalence of stress and its effects on general physical health among the SCHS residency training physicians. Therefore, this study was initiated to investigate the prevalence of stress among the SCHS residency trainees in three residency training programs, namely, Family Medicine, Emergency Medicine, and Internal Medicine and its association with other study variables.

\section{Participants and methods Study subjects}

The participants were male and female postgraduate medical residency trainees in the College of Medicine, King Saud University, King Fahad Hospital and Military Hospital, who were selected through the SCHS, Riyadh, Saudi Arabia. The participants were from the 1 st to 4 th year (R-1 to R-4) resident trainees and were undergoing training in Emergency Medicine, Internal Medicine, and Family Medicine programs. The data were collected during mid of the academic year 2014-2015.

\section{Data collection methods}

An anonymous, self-administered, and bilingual questionnaire (Arabic and English) Kessler 10 Psychological Distress (K10) instrument was employed to measure stress levels. ${ }^{16}$ The questionnaires were distributed to a total of 389 residence trainees and data were collected. All participating residence trainees were informed by a written consent form about the objectives of the study and given an explanation about the contents of the questionnaire. The questionnaire included three different parts. The first part contained demographic information about the participants, the second part contained distress instrument (Kessler 10), and the third part contained additional information related to general physical health problem, absent days from workplace, and inefficient day activities, due to stress, during the past 4 weeks. A nonrandom, convenient sampling technique was employed to collect the data due to the varied distribution of residence in three different specialties. All participants were allowed to respond at their convenience and available times, and their privacy was secured. Also, participation was entirely voluntary. We have kept track of the three specialties by assigning numbers to the questionnaire forms.

\section{Instrument}

In the present study, we have used validated Kessler-10 Psychological Distress instrument (K10) developed by Kessler et al. ${ }^{16}$ This instrument has been widely used in population-based epidemiological studies to measure the current (4 weeks) stress and was translated in different languages, including Arabic, to measure the level of stress and severity associated with psychological symptoms in population surveys. ${ }^{17-19}$ The K10 consists of ten questions in the form of "how often in the past month did you feel" and offers specific symptoms, such as "tired out for no good reason", "nervous", and "sad or depressed". The five possible responses for each question range from "none of the time" to "all of the time" and were scored from 1 to 5 respectively. All the questions were collated to obtain a total score. The total scores were interpreted as follows: a score of $<20$ will be considered not to represent stress of any level; a score of 20-24 represents mild stress; 25-29 represents moderate stress; and 30-50 represents severe stress. ${ }^{16}$ 


\section{Exclusion criteria}

The resident trainees who were not selected through SCHS residency training program, were having postgraduate or other examination in less than 2 weeks, suffered from any known debilitating disease, and had previous psychiatric illness history were excluded from the study.

\section{Statistical analysis}

Numerical data were entered in Microsoft Excel and analyzed using SPSS Statistics, version 19.0 (IBM Corporation, Armonk, NY, USA). The prevalence of an outcome variable along with $95 \%$ confidence intervals was calculated. Pearson's chi-square test and odds ratios (ORs) were used to evaluate and quantify the associations between a categorical outcome and the variables under consideration. The statistical significance level was maintained as $P<0.05$ during the entire analysis.

\section{Ethical consideration}

The study was approved by the research ethical committee of the College of Medicine, King Saud University, Riyadh, Saudi Arabia.

\section{Results}

A total of 318 (out of 389 , with the response rate of $82 \%$ ) resident trainee physicians completed K10 questionnaires. The age of the study participants was $27.9 \pm 1.6$ years (mean \pm standard deviation [SD]). The participants' demographic information is presented in Table 1.

The K10 score was normally distributed among the resident trainees (mean score $=23.65, \mathrm{SD} \pm 6.76$ ). The prevalence of stress among the resident trainee physicians was high (70.4\%), which comprised of mild (27.4\%), moderate (20.4\%), and severe (22.6\%) stress levels.

The prevalence of overall stress was highest among the resident trainees at R-1 (85.3\%) followed by R-2 (75.6\%), R-3 (58.8\%), and R-4 (51.0\%) levels $\left(\chi^{2}=26.25 ; P=0.0001\right)$ (Table 2). The mild level of stress was significantly higher in $\mathrm{R}-1(\mathrm{OR}=3.2 ; P=0.019)$ and $\mathrm{R}-2(\mathrm{OR}=2.9 ; P=0.021)$ as compared to the R-4 (Table 3). The ORs of moderate stress level were also significantly higher during $\mathrm{R}-1(\mathrm{OR}=5.87 ; P=0.001)$ and R-2 ( $\mathrm{OR}=4.60 ; P=0.005)$, while R-4 was considered the reference category. However, ORs of severe stress level were quite high during $\mathrm{R}-1$ ( $\mathrm{OR}=11.15, P<0.0001)$, as compared to $\mathrm{R}-2(\mathrm{OR}=2.33, P=0.104)$ and $\mathrm{R}-4(\mathrm{OR}=1.29, P=0.639)$ levels, while the R-3 level was considered the reference category.

The prevalence of overall stress was highest among the resident trainees of Emergency Medicine (80.5\%), followed
Table I Demographic information of participants (resident trainees)

\begin{tabular}{ll}
\hline Participants & $\mathbf{n}(\%)$ \\
\hline Sex & \\
Male & $19 I(60.1)$ \\
Female & $127(39.9)$ \\
Marital status & \\
Unmarried & $15 I(47.5)$ \\
Married & $167(52.5)$ \\
Specialties & \\
Emergency medicine & $4 I(12.9)$ \\
Family medicine & $114(35.8)$ \\
Internal medicine & $163(51.3)$ \\
Residency years (levels) & \\
Year I (R-I) & $102(32.1)$ \\
Year 2 (R-2) & $82(25.8)$ \\
Year 3 (R-3) & $85(26.7)$ \\
Year 4 (R-4) & $49(15.4)$ \\
Stress level & \\
No & $94(29.6)$ \\
Mild & $87(27.4)$ \\
Moderate & $65(20.4)$ \\
Severe & $72(22.6)$ \\
\hline
\end{tabular}

by Internal Medicine (75.6\%), and Family Medicine (62.3\%) $\left(\chi^{2}=6.42 ; P=0.04\right)$ (Table 2$)$. The ORs of the resident trainees of the Emergency Medicine were quite high in severe stress level $(\mathrm{OR}=5.57 ; P=0.0005)$ and Internal Medicine $(\mathrm{OR}=1.74 ; P=0.124)$ in comparison to the Family Medicine. Similarly, moderate stress level was highest among the Emergency Medicine (OR =2.55) and Internal Medicine $(\mathrm{OR}=1.95)$ resident trainees in comparison to the Family Medicine trainees (Table 3).

The study results also showed a high level of overall stress among the Emergency Medicine trainees during R-1

Table 2 Overall stress level in medical residency trainees

\begin{tabular}{llll}
\hline Participants & $\begin{array}{l}\text { No } \\
\text { n (\%) }\end{array}$ & $\begin{array}{l}\text { Yes } \\
\text { n (\%) }\end{array}$ & $\begin{array}{l}\chi^{2} \\
\text { P-value }\end{array}$ \\
\hline Sex & & & \\
$\quad$ Male & $59(30.9)$ & $132(69.1)$ & 0.52 \\
$\quad$ Female & $35(27.6)$ & $92(72.4)$ & 0.406 \\
Marital status & & & \\
$\quad$ Unmarried & $40(26.5)$ & III (73.5) & 1.30 \\
$\quad$ Married & $54(32.3)$ & II $3(67.7)$ & 0.254 \\
Specialties & & & \\
$\quad$ Emergency medicine & $8(19.5)$ & $33(80.5)$ & 6.42 \\
$\quad$ Family medicine & $43(37.7)$ & $71(62.3)$ & 0.040 \\
$\quad$ Internal medicine & $43(26.4)$ & $120(73.6)$ & \\
Residency years (levels) & & & \\
$\quad$ Year I (R-I) & $15(14.7)$ & $87(85.3)$ & 26.25 \\
$\quad$ Year 2 (R-2) & $20(24.4)$ & $62(75.6)$ & 0.000 I \\
$\quad$ Year 3 (R-3) & $35(41.2)$ & $50(58.8)$ & \\
$\quad$ Year 4 (R-4) & $24(49.0)$ & $25(51.0)$ & \\
\hline
\end{tabular}




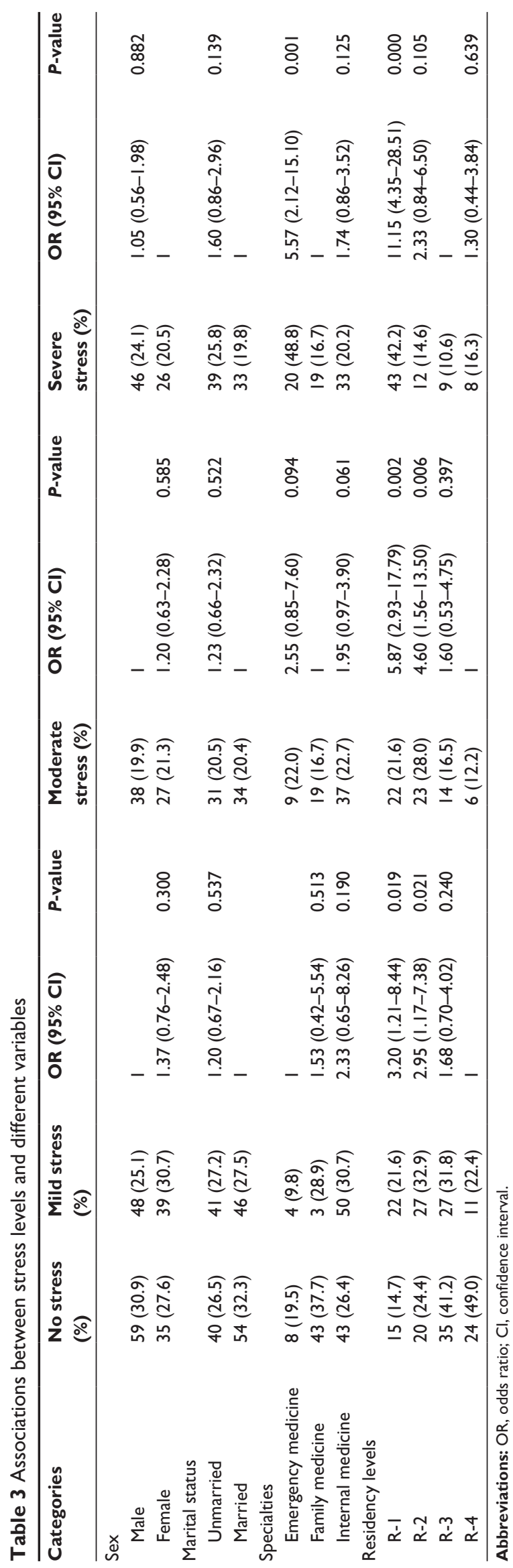

(100\%) and R-2 (100\%) which decreased during R-3 (63\%) and R-4 $(17 \%)$ training levels $\left(\chi^{2}=23.755, P<0.0001\right)$. The distribution of overall stress level among the Internal Medicine trainees was also high in R-1 (97\%), followed by R-2 (86\%), R-3 (50\%), and R-4 (23\%) training levels $\left(\chi^{2}=60.123\right.$, $P<0.0001)$. However, distribution of overall stress level among the Family Medicine trainees during R-4 was quite high (90\%), followed by R-3 (66\%), R-2, and R-1 (48\%) $\left(\chi^{2}=11.80, P=0.008\right)$.

The association between a person's sex and their stress levels was not statistically significant $\left(\chi^{2}=0.52, P=0.406\right.$ ). The prevalence of moderate stress was slightly higher in female resident trainees as compared to the male resident trainees ( $O R=1.20)$. However, severe stress levels of male and female resident trainees were almost equal $(\mathrm{OR}=1.05)$. The association between stress levels in married and unmarried resident trainees was not statistically significant $\left(\chi^{2}=1.30, P=0.254\right)$. However, prevalence of severe stress in unmarried trainee residents was slightly higher as compared to the married trainee residents $(\mathrm{OR}=1.60)$.

The stress level during the residency training has an effect on the efficiency of day activities; and therefore, inefficient activities have been reported $1-2$ days by $45.5 \%$ trainees, $3-4$ days by $14.7 \%$ trainees, and $\geq 5$ days by $7.2 \%$ trainees $\left(\chi^{2}=28.48, P<0.0001\right)$. The stress levels also have an effect on the presence of resident trainees in the workplace. Overall, $22.8 \%$ of stressed trainees were absent for $1-2$ days, $34.4 \%$ trainees were absent for 3-4 days, $13.9 \%$ trainees were absent for 5-6 days, and $22.3 \%$ trainees were absent for $\geq 7$ days during the past 4 weeks $\left(\chi^{2}=39.15 ; P<0.0001\right)$ (Table 4$)$.

Table 4 Stress level and its associations with working efficiency and general health problem

\begin{tabular}{|c|c|c|c|c|}
\hline \multirow[t]{2}{*}{ Parameters } & \multirow[t]{2}{*}{ No (\%) } & \multicolumn{2}{|c|}{ Stress level } & \multirow{2}{*}{$\begin{array}{l}\chi^{2} \\
P \text {-value }\end{array}$} \\
\hline & & Mild (\%) & $>$ mild $(\%)$ & \\
\hline \multicolumn{5}{|c|}{ Inefficient day activities } \\
\hline 0 day & $57(43.8)$ & $40(30.8)$ & $33(25.4)$ & 42.62 \\
\hline I-3 days & $36(21.7)$ & $45(27.1)$ & $85(5 \mid .2)$ & $<0.0001$ \\
\hline 4-6 days & $0(0.0)$ & $2(15.4)$ & II (84.6) & \\
\hline$\geq 7$ days & $0(0.0)$ & $I(I I . I)$ & $8(88.9)$ & \\
\hline \multicolumn{5}{|c|}{ Absent days from workplace } \\
\hline 0 day & $15(50.0)$ & $10(33.3)$ & $5(16.7)$ & 49.63 \\
\hline I-3 days & $65(40.6)$ & $43(26.9)$ & $52(32.5)$ & $<0.0001$ \\
\hline 4-6 days & $12(15.8)$ & $21(27.6)$ & $43(56.6)$ & \\
\hline$\geq 7$ days & $2(3.8)$ & $13(25.0)$ & 37 (7I.2) & \\
\hline \multicolumn{5}{|c|}{ General health problems } \\
\hline None of the time & $23(52.3)$ & II (25.0) & $10(22.7)$ & 52.90 \\
\hline Little of the time & $61(39.9)$ & $40(26.1)$ & $52(34.0)$ & $<0.0001$ \\
\hline Some of the time & $9(9.2)$ & $32(32.7)$ & $57(58.2)$ & \\
\hline Most of the time & $\mathrm{I}(4.3)$ & $4(17.4)$ & $18(78.3)$ & \\
\hline
\end{tabular}


Also, during the past 4 weeks, $10 \%$ of stressed population of trainees visited physicians due to self-perception of physical health problem $\left(\chi^{2}=45.27 ; P<0.0001\right)$ (Table 4).

\section{Discussion}

This is the first study which has explored the stress level among the resident trainees of SCHS, and its effect on working efficiency. Previously, the authors have studied the prevalence of stress among Saudi medical students during undergraduate and during internship training using the same instrument. ${ }^{17-19}$ During the undergraduate period, the stress level was $63 \%$, with which severe stress being experienced by $25 \%$, whereas during internship training stress level was $73.0 \%$, with severe stress being experienced by $34.9 \%$. The present study showed that the overall stress level was also high (70.4\%), but the severe stress level among the resident trainees is lower than the medical undergraduate students and internship trainees. The results indicated severe stress levels (22.6\%). Most of the reports stated that the careers in medicine have been known to be stressful. ${ }^{20-22}$ The stress levels of resident trainees in medicine specialty agree to some extent with those of reports stating that depressive symptoms range from $16 \%$ to $35 \%$ during residency training. ${ }^{23-25}$

The prevalence of stress in R-1 Internal Medicine and Emergency Medicine resident trainees was quite high (stress score $=26.7$ ) and gradually decreased in R-2 (stress score $=23.2$ ), R-3 (stress score $=21.8$ ), and R-4 (stress score $=21.4$ ). The prevalence of stress in resident trainees fell with each successive year of training, and this is also reported by another study. ${ }^{26}$ The stress level of R-1 resident trainees may be due to lack of control over time management, work planning, work organization, and interpersonal relationships. ${ }^{3,27}$ The other likelihood criteria of stress in early years of resident training could be due to mood fluctuation, dissatisfaction with clinical faculty, or family stress. The residents who are more senior in training are also stressful due to the fierce competition lying ahead in the form of postgraduate examination, responsibility, high expectations, and suitable jobs. Stress level in the Family Medicine resident trainees was lower in early years of training and gradually increased in the R-4 training year. A local study reported that the Family Medicine residents are being overloaded with many scheduled and unscheduled assignments during the R-4 year of training, and they also have heavy clinical duties and execute a compulsory research project. These factors could explain the increasing stress level in their final training year. ${ }^{28}$
The study did not show stress score differences between male and female resident trainees. However, female resident trainees had a slightly higher prevalence of stress than their male counterparts in different specialties, but the result was not statistically significant. This finding is consistent with other international studies in which no statistical significant differences between the stress levels of male and female students were reported using the same tool ${ }^{28}$ or using different tools..$^{29,30}$ Our findings are, to some extent, in agreement with the few international reports, in which female medical trainees reported higher stress level than the male trainee physicians during their postgraduate training years. ${ }^{31,32}$ Our previous studies also found higher prevalence of stress among female medical undergraduate students and interns compared to the male counterparts. ${ }^{17,19}$ This may be attributed to multiple factors, such as social, cultural, and religious factors, which isolate females themselves from male-related/involved activities at their workplaces.

Marital status and its positive association with stress level did not show in the whole study population. Similarly, previous national and international studies did not observe significant differences in depression and anxiety scores among the married and unmarried medical students and physicians. ${ }^{17,33,34}$ However, a study showed that marital status is a protective factor against depression, because the enduring relationship acts as a sort of insurance against psychological illness. ${ }^{17}$

This study also found that high stress was significantly associated with residents' general health problems. The higher stress score was among the resident trainees who have reported physical problems most of the time (stress score $=30.57$ ) in comparison to those who have reported physical problems some of the time (stress score $=25.88$ ) and a little of the time (stress score $=22.18$ ). The resident trainees who had high stress scores also reported significantly more days of being unable to work and inefficiency in daytime activities. The result is consistent with other studies in which stress was significantly associated with students' general health problem and decreased working efficiency. ${ }^{18,28}$ The psychological distress and the associated physical symptoms might have a negative impact on residents' professional and academic performance. A study indicated that work-related stress can affect a doctor's health and may result in poor morale, motivation, communication, and decision-making, as well as poor relationships with colleagues. ${ }^{35}$

Although the study had a high response rate, one limitation of the study is that it was a cross-sectional study and not a cohort one, and the different levels of stress in the different 
groups of the trainee need to be interpreted with caution. The increasing and decreasing levels of stress could be by chance. Therefore, a cohort study should be conducted to follow up the same cohort up to the completion of the 4-year residency programs, to identify actual effects of the different training years.

\section{Conclusion}

The present study showed a relatively high prevalence of stress among the resident trainees of the SCHS in three postgraduate programs. The findings suggest that there are high levels of perceived stress in Emergency Medicine followed by Internal Medicine and Family Medicine during the period of training. The high stress level decreased efficient daytime activity and made the trainees absent from the workplace. Our findings could be helpful for the SCHS administrators and as a basis for an interventional study to tackle this important problem.

\section{Acknowledgments}

The authors are grateful to all training physicians who have actively participated in the study and gave their precious time to complete all data required for the study. The study was funded by the College Research Center, Deanship of Scientific Research, King Saud University, Riyadh, Saudi Arabia.

\section{Disclosure}

The authors report no conflicts of interest in this work.

\section{References}

1. Yousuf A, Ishaque S, Qidwai W. Depression and its associated risk factors in medical and surgical post graduate trainees at a teaching hospital: a cross sectional survey from a developing country. J Pak Med Assoc. 2011;61:968-973.

2. Rubin R. Recent suicides highlight need to address depression in medical students and residents. JAMA. 2014;312:1725-1727.

3. Cohen JS, Patten S. Well-being in residency training: a survey examining resident physician satisfaction both within and outside of residency training and mental health in Alberta. BMC Med Educ. 2005; 22:1-21.

4. Collier VU, McCue JD, Markus A, Smith L. Stress in medical residency: status quo after a decade of reform? Ann Intern Med. 2002;136: 384-390.

5. Shanafelt TD, Bradley KA, Wipf JE, Back AL. Burnout and self-reported patient care in an internal medicine residency program. Ann Intern Med. 2002;136:358-367.

6. Sen S, Kranzler HR, Krystal JH, et al. A prospective cohort study investigating factors associated with depression during medical internship. Arch Gen Psychiatry. 2010;67:557-565.

7. Taylor SE. Mechanisms linking early life stress to adult health outcomes. Proc Natl Acad Sci. 2010;107:8507-8512.

8. Lupien SJ, McEwen BS, Gunnar MR, Heim C. Effect of stress throughout the lifespan on the brain, behaviour and cognition. Nature. 2009;10: 434-445.
9. The human brain. 2004. Available from: http://learn.fi.edu/learn/brain/ stress.html. Accessed June 14, 2015.

10. Yao DC, Wright SM. National survey of internal medicine residency training program directors regarding problem residents. JAMA. 2000; 284:1099-1104.

11. Levey RI. Sources of stress for residents and recommendations for programs to assist them. Acad Med. 2001;70(20):142-150.

12. Issa BA, Yussuf AD, Olanrewaju GT, Oyewole AO. Stress in residency training as perceived by resident doctors in a Nigerian university teaching hospital. Eur J Sci Res. 2009;30:253-259.

13. Maslach C, Shaufeli W, Leiter M, Goldberg J. Job burnout: new directions in research and intervention. Curr Dir Psychol Sci. 2003;12:189-192.

14. Al Jadid MS. Rehabilitation medicine in the Kingdom of Saudi Arabia. Saudi Med J. 2011;32:962-963.

15. Bajammal S, Zaini R, Abuznadah W, et al. The need for national medical licensing examination in Saudi Arabia. BMC Med Educ. 2008;25:53.

16. Kessler RC, Andrews G, Colpe LJ, et al. Short screening scales to monitor population prevalences and trends in non-specific psychological distress. Psychol Med. 2002;32:959-976.

17. Abdulghani HM, Irshad M, Al Zunitan MA, et al. Prevalence of stress in junior doctors during their internship training: a cross-sectional study of three Saudi medical colleges' hospitals. Neuropsychiatr Dis Treat. 2014; 25:1879-1886.

18. Abdulghani HM. Stress and depression among medical students: a cross sectional study at a medical college in Saudi Arabia. Pak J Med Sci. 2008;24:12-17.

19. Abdulghani HM, AlKanhal AA, Mahmoud ES, Ponnamperuma GG, Alfaris EA. Stress and its effects on medical students: a cross-sectional study at a college of medicine in Saudi Arabia. J Health Popul Nutr. 2011;29:516-522.

20. Prins JT, Gazendam-Donofrio SM, Tubben BJ, van der Heijden FM, van de Wiel HB, Hoekstra-Weebers JE. Burnout in medical residents: a review. Med Educ. 2007;41:788-800.

21. Lee J, Alferi M, Patel T, Lee L. Choosing family medicine residency programs: what factors influence residents' decisions? Can Fam Physician. 2011;57:e113-e121.

22. Hoonpongsimanont W, Murphy M, Kim CH, Nasir D, Compton S. Emergency medicine resident well-being: stress and satisfaction. Occup Med. 2014;64:45-48.

23. Goebert D, Thompson D, Takeshita J, et al. Depressive symptoms in medical students and residents: a multischool study. Acad Med. 2009; 84:236-241.

24. Demir F, Ay P, Erbas M, Ozdil M, Yasar E. The prevalence of depression and its associated factors among resident doctors working in a training hospital in Istanbul. Turk Psikiyatri Derg. 2007;18:31-37.

25. Haqqi S, Areeb SB, Haseeb A, Ali NF, Hashim H. The prevalence of depression among resident doctors in a teaching hospital. Pak J Med Dent. 2013;2:16-20.

26. Reuben DB. Depressive symptoms in medical house officers. Effects of level of training and work rotation. Arch Intern Med. 1985;145: 286-298.

27. Nyssen AS, Hansez I, Baele P. Occupational stress and burnout in anaesthesia. Br J Anaesth. 2003;90:333-337.

28. Koochaki GM, Charkazi A, Hasanzadeh A, Saedani M, Qorbani M, Marjani A. Prevalence of stress among Iranian medical students: a questionnaire survey. East Mediterr Health J. 2011;17:593-598.

29. Moffat KJ, McConnachie A, Ross S, Morrison JM. First year medical student stress and coping in a problem-based learning medical curriculum. Med Educ. 2004;38:482-491.

30. Niemi PM, Vainiomäki PT. Medical students' distress, quality, continuity and gender differences during a six-year medical programme. Med Teach. 2006;28:136-141.

31. Yogev S, Harris S. Women physicians during residency years: workload, work satisfaction and self-concept. Soc Sci Med. 1983;17:837-841.

32. Gramstad TO, Gjestad R, Haver B. Personality traits predict job stress, depression and anxiety among junior physicians. BMC Med Educ. 2013; 13:150. 
33. El-Masry R, Ghreiz SM, Helal RM, Audeh AM, Shams T. Perceived stress and burnout among medical students during the clinical period of their education. Ibnosina J Med Biomed Sci. 2013;5:179-188.

34. Gu A, Onyeama GM, Bakare MO, Igwe MN. Prevalence of depression among resident doctors in a teaching hospital, South East Nigeria. Int J Clin Psychiatry. 2015;3:1-5.
35. Stebbing J, Mandalia S, Portsmouth S, et al. A questionnaire survey of stress and bullying in doctors undertaking research. Postgrad Med J. 2004;80:93-96.

\section{Publish your work in this journal}

Neuropsychiatric Disease and Treatment is an international, peerreviewed journal of clinical therapeutics and pharmacology focusing on concise rapid reporting of clinical or pre-clinical studies on a range of neuropsychiatric and neurological disorders. This journa is indexed on PubMed Central, the 'PsycINFO' database and CAS, and is the official journal of The International Neuropsychiatric Association (INA). The manuscript management system is completely online and includes a very quick and fair peer-review system, which is all easy to use. Visit http://www.dovepress.com/testimonials.php to read real quotes from published authors.

Submit your manuscript here: http://www.dovepress.com/neuropsychiatric-disease-and-treatment-journal 